\title{
Inhibitory Effect of Fluconazole Combined with Amphotericin B on Fluconazole-Resistant Candida albicans Biofilm Formation
}

\author{
Sara Neamati ${ }^{1}$ (D), Alireza Khodavandi ${ }^{2}$ (D) Fahimeh Alizadeh $^{1}$ (D) \\ 1. Dept. of Microbiology, Yasooj Branch, Islamic Azad University, Yasooj, Iran \\ 2. Dept. of Biology, Gachsaran Branch, Islamic Azad University, Gachsaran, Iran
}

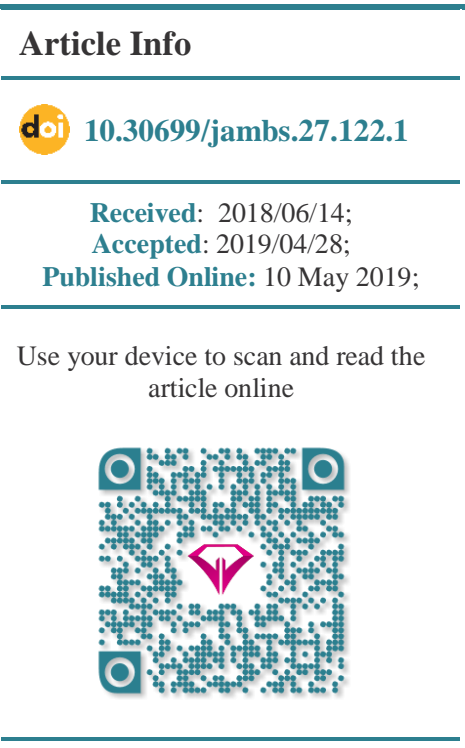

Corresponding Information: Alireza Khodavandi, Dept. of Biology, Gachsaran Branch, Islamic Azad University, Gachsaran, Iran Email:

alireza_khodavandi@yahoo.com,

\begin{abstract}
Background \& Objective: The incidence of biofilm-related infections caused by Candida albicans has increased dramatically. C. albicans biofilm-related infections are more resistant to antifungal medications. This work was an attempt to examine inhibitory effects of fluconazole in combination with amphotericin B on fluconazoleresistant $C$. albicans biofilm.
\end{abstract}

Materials \& Methods: Fluconazole-resistant $C$. albicans was identified among colonized clinical isolates of $C$. albicans obtained from the patients at Shahid Beheshti Hospital, Yasooj, Iran, between September 2016 and January 2017. The MICs of fluconazole alone and in combination with amphotericin B were determined on fluconazole-resistant $C$. albicans by broth microdilution method based on the CLSI document M27-A3 and the synergistic effects were interpreted by the FIC index. To address the inhibitory effects of drug combinations, we investigated the anti-biofilm activities of fluconazole alone and in combination with amphotericin B against fluconazole-resistant $C$. albicans using crystal violet staining, light field microscopy and expression analysis of $H W P 1$ using RT-PCR.

Results: Ten percent of the colonizing clinical isolates of $C$. albicans were found to be fluconazole-resistant. The fluconazole combined with amphotericin B exhibited synergistic and partial synergistic effects against fluconazole-resistant $C$. albicans isolates with FIC index ranging from 0.50 to 0.75 . Our findings demonstrated that fluconazole combined with amphotericin B exerted a significant reduction and inhibition on biomass, biofilm formation and the expression levels of HWP1 $(P<0.05)$.

Conclusion: Fluconazole combined with amphotericin B showed potent inhibitory activity against fluconazole-resistant $C$. albicans biofilm formation. Other measures are important to determine the effectiveness of the drug combinations against $C$. albicans biofilm.

Keywords: Amphotericin B, Antifungal agents, Biofilm, Candida albicans, Fluconazole

\section{Introduction}

Candida biofilms have been associated with the severe resistance to antifungal agents compared to their planktonic cells $(\mathbf{1}, 2)$. Candida albicans is the most common fungal pathogen associated with the biofilmrelated infections. Biofilm formation of Candida has gained considerable attention due to its contributions to the unacceptably high rates of mortality in the immunocompromised hosts $(3,4)$. The biofilms communities are organized, structured, coordinated and functional communities of cells, in which a matrix of exopolymeric substances is embedded $(2,4,5)$.

A variety of transcriptional regulations determine the process of biofilm formation in $C$. albicans. Nine master regulatory genes; BCRl, BRG1, EFG1, FLO8, GALA, NDT80, ROB1, RFX2 and TEC1 are required to control both themselves and approximately 1000 target genes involved in the biofilm formation in $C$. albicans such as hyphal morphogenesis (e.g., $H W P 1$ ), extracellular matrix production (e.g., GSCl and $M N N 1$ ), and drug resistance (e.g., CDRl and MDRl) (6-9). Hyphal Wall Protein 1 (encoded by $H W P 1$ ) is a well-characterized $C$. albicans hypha-associated cell surface protein that mediates the adhesion to the epithelial cells, as well as biofilm formation $(10,11)$.

A few classes of antifungal drugs such as polyenes, azoles, allylamines, echinocandins and miazines are in common use for the treatment of Candida species infections. Polyenes (e.g., amphotericin B) are fungicidal, intercalating into membranes containing ergosterol and form membrane pores that destroy the cell contents. The most widely used group is azoles (e.g., fluconazole) which possess fungistatic effect by inhibition of the lanosterol 
$14 \alpha$-demethylase which leads to an accumulation of the toxic sterol pathway intermediates $(2,12)$. Due to the limited number of antifungal agents and increased resistance of biofilm cells, therapeutic options available in the treatment of Candida infections are exceedingly insufficient. The development of new class of antifungal agents is not easy; therefore, this problem might be alleviated using drug combinations. Moreover, reports showed that drug combination is highly effective for the eradication of Candida biofilm $(13,14)$.

Given the synergistic efficacy of fluconazole along with amphotericin B against $C$. albicans (15), we hypothesized that fluconazole combined with amphotericin B could augment the efficacy on the biofilm formation inhibition on fluconazole-resistant $C$. albicans. In this study, we evaluated the in vitro efficacy of fluconazole alone and in combination with amphotericin B against fluconazoleresistant $C$. albicans and observed their antimicrobial effects on the biofilm formation. In addition, crystal violet (CV) staining, microscopic analysis of biofilm formation and the expression analysis of hypha specific gene (HWP1) were investigated on fluconazole-resistant $C$. albicans.

\section{Materials and Methods}

\section{Organism}

The reference strains of $C$. albicans ATCC 10231 strain 3147 [C. albicans Drug Resistance Panel (ATCC® MP$\left.8^{\mathrm{TM}}\right)$ ] and $C$. albicans CBS 5982 were used in this study. Fluconazole susceptibility was studied on 100 colonized clinical isolates of $C$. albicans obtained from 100 pregnant women, diabetics, cancer and maintenance hemodialysis patients at Shahid Beheshti Hospital, Yasooj, Iran, between September 2016 and January 2017. Fluconazole susceptibility of clinical isolates of $C$. albicans was determined using CSLI M27-A3 document with slight modification (16).

Combination Testing of Fluconazole with Amphotericin B on Fluconazole-Resistant Candida albicans

The effects of fluconazole alone and in combination with amphotericin B were tested against fluconazole-resistant $C$. albicans by broth microdilution method using CLSI document (M27-A3) with slight modification. Briefly, the inocula from $24 \mathrm{~h} \mathrm{C}$. albicans cultures on Sabouraud Dextrose Agar (SDA, Merck Research Laboratories, Germany) were prepared to a turbidity equivalent to a 0.5 McFarland standard with a spectrophotometer at $530 \mathrm{~nm}$. The $C$. albicans suspensions were further diluted to yield an inoculum concentration of approximately $5 \times 10^{2}-2.5 \times 10^{3}$ cells/mL in Roswell Park Memorial Institute (RPMI)-1640 medium (Sigma-Aldrich) with $0.2 \%$ glucose [buffered to pH 7.0 with $0.165 \mathrm{M}$ morpholinophos- phonyl sulfate (MOPS)]. The minimal inhibitory concentration (MIC) assay was performed with 96 -well plates. C.albicans inoculum $(100 \mu \mathrm{L})$ was exposed to $100 \mu \mathrm{L}$ of the two-fold dilutions of the fluconazole (ranging $0.0313-64 \mu \mathrm{g} / \mathrm{mL}$ ) and amphotericin B (ranging $0.0313-16 \mu \mathrm{g} / \mathrm{mL}$ ) alone and in combination. The fluconazole and amphotericin B in combination were mixed in 1:1 ratio. The microplates were kept at $4^{\circ} \mathrm{C}$ for $2 \mathrm{~h}$ and incubated at $35^{\circ} \mathrm{C}$ for $24 \mathrm{~h}$ to evaluate the MICs. The end points of $\geq 50 \%$ and $\geq 90 \%$ reduction in turbidity relative to the positive control were determined using a Stat Fax 303 Reader (Awareness Technology, Inc., USA) at $530 \mathrm{~nm}$.

To evaluate the interaction between fluconazole and amphotericin B, the FIC index was calculated from the data obtained with relative MICs determination with the antifungal alone and in combination as described earlier $(16,17)$.

Combination Testing of Fluconazole with Amphotericin B on Fluconazole-Resistant Candida albicans Biofilm Formation

The biofilm formation assay was performed exactly as described previously (18-21). Combination testing of fluconazole with amphotericin B on fluconazole-resistant C. albicans biofilm formation was determined by crystal violet (cv) staining, microscopic analysis of biofilm formation and the expression analysis of $C$. albicans hypha specific gene.

The yeast cell suspension $\left(1 \times 10^{6}\right.$ cells $\left./ \mathrm{mL}\right)$ was dispensed into the wells of 96-well plates $(100 \mu \mathrm{L} /$ well). The wells were filled with $100 \mu \mathrm{L}$ of four different concentrations based on the MIC values $(2 \times \mathrm{MIC}, 1 \times \mathrm{MIC}$, $1 / 2 \times \mathrm{MIC}$ and $1 / 4 \times \mathrm{MIC}$ ) of fluconazole alone or in combination with amphotericin $\mathrm{B}$. After incubation at $35^{\circ} \mathrm{C}$ for $90 \mathrm{~min}$, the plates were incubated again at $35^{\circ} \mathrm{C}$ for 24 $\mathrm{h}$ with gentle shaking. After fixation of biofilm with $99 \%$ methanol, they were stained by aqueous crystal violet for $20 \mathrm{~min}$ and de-stained using 33\% acetic acid. The absorbance values were obtained at $590 \mathrm{~nm}$ using Stat Fax 303 Reader $(18,19)$.

The effect of fluconazole alone or in combination with amphotericin B on fluconazole-resistant C. albicans (ATCC 10231) biofilm formation was qualitatively analyzed by the light field microscope. The biofilms were formed on glass cover slips in 6-well cell culture plates by growing the cells $\left(1 \times 10^{6}\right.$ cells $\left./ \mathrm{mL}\right)$ in RPMI-1640 treated with four different concentrations based on the MIC values ( $2 \times \mathrm{MIC}, 1 \times \mathrm{MIC}, 1 / 2 \times \mathrm{MIC}$ and $1 / 4 \times \mathrm{MIC})$ of fluconazole alone or in combination with amphotericin B. The microplates were incubated at $35^{\circ} \mathrm{C}$ for $90 \mathrm{~min}$, and then maintained for $24 \mathrm{~h}$ with gentle shaking at $35^{\circ} \mathrm{C}$. Thereafter, the cover slips were washed with PBS and visualized with the Leica light field microscope using 40X objective lens $(19,20)$.

Subsequently, the effect of fluconazole alone or in combination with amphotericin B was evaluated on the expression of hypha specific gene (HWP1) on fluconazoleresistant $C$. albicans (ATCC 10231) biofilm formation by two-step reverse transcription polymerase chain reaction (RT-PCR). The biofilms were formed on 96-well plates by growing the cells $\left(1 \times 10^{6}\right.$ cells $\left./ \mathrm{mL}\right)$ in RPMI-1640 treated with four different concentrations based on the MIC values ( $2 \times \mathrm{MIC}, 1 \times \mathrm{MIC}, 1 / 2 \times \mathrm{MIC}$ and $1 / 4 \times \mathrm{MIC})$ of fluconazole alone or in combination with amphotericin $\mathrm{B}$ and total RNA of the cells was extracted using the RNeasy Mini Kit (Qiagen, Hilden, Germany). The cDNA was synthesized 
from DNase I-treated total RNA using Moloney-Murine Leukemia Virus reverse transcriptase and random hexamers (Fermentas, USA). The RT-PCR reaction was conducted using the primers for the target HWPI and housekeeping internal control Beta actin genes (Table 1). The RT-PCR was performed in TPersonal thermocycler (Biometra- Germany) with an initial denaturation at $95^{\circ} \mathrm{C}$ ( $4 \mathrm{~min}$ ), followed by 26 cycles of denaturation $\left(94^{\circ} \mathrm{C} / 40 \mathrm{sec}\right)$, annealing $\left(56^{\circ} \mathrm{C} / 45 \mathrm{sec}\right)$ and extension $\left(72^{\circ} \mathrm{C} / 45 \mathrm{sec}\right)$, and final extension at $72^{\circ} \mathrm{C}$ for $10 \mathrm{~min}$. The specificity of the primers was confirmed by the sequencing analysis (First BASE Laboratories Sdn. Bhd., Malaysia). The amplified products were analyzed by Quantity One 1D Analysis (Bio-Rad, USA, version 4.6). The relative quantification of the target transcripts were determined by the volume-based analysis comparing to DNA mass standard (Fermentas, USA) (19-21)

\section{Statistical Analysis}

All the experiments were performed in triplicate. Data were analyzed using the statistical software SPSS 23.0 (SPSS Inc., Chicago, IL., USA). All data were expressed as mean values with the corresponding standard deviations (SD). The comparisons were performed using one-way ANOVA, with Tukey's HSD post hoc test. A P-value less than 0.05 was considered statistically significant.

Table 1. Oligonucleotide primers used for RT-PCR

\begin{tabular}{|c|c|c|c|}
\hline Primer & Orientation & Sequence & Reference \\
\hline \multirow[t]{2}{*}{$H W P 1$} & Forward & 5’ GGTAGACGGTCAAGGTGAAACA 3' & \multirow{2}{*}{$(21)$} \\
\hline & Reverse & 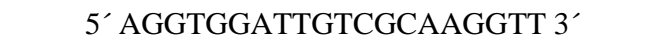 & \\
\hline \multirow[t]{2}{*}{ Beta actin } & Forward & $5^{\prime}$ ACCGAAGCTCCAATGAATCCAAAATCC 3' & \multirow{2}{*}{$(20)$} \\
\hline & Reverse & 5' GTTTGGTCAATACCAGCAGCTTCCAAA 3' & \\
\hline
\end{tabular}

\section{Results}

Hundred colonized $C$. albicans isolated from the clinical samples were identified and used for the fluconazole susceptibility testing. Ten fluconazoleresistant $C$. albicans were identified and used in the study. For fluconazole-resistant $C$. albicans, the relative MIC of fluconazole was $\geq 16 \mu \mathrm{g} / \mathrm{mL}$ when used alone. The $90 \%$ of fluconazole-resistant $C$. albicans isolates were resistant to amphotericin B with MIC $\geq 2.0 \mu \mathrm{g} / \mathrm{mL}$. The susceptibility assay showed that the combination of fluconazole and amphotericin B was synergistic $(20 \%)$, partial synergistic $(20 \%)$, additive $(30 \%)$ and indifferent $(30 \%)$ as antifungal effects against fluconazole-resistant $C$. albicans (Table 2). Combination of fluconazole and amphotericin B exhibited synergistic and partial synergistic effects against fluconazole-resistant $C$. albicans isolates with FIC index ranged from 0.50 to 0.75

Table 3 shows the corresponding results for the reduction of biomass determined by the $\mathrm{CV}$ staining of the inhibitory effect of fluconazole combined with amphotericin B on fluconazole-resistant $C$. albicans biofilm at different concentrations based on the MIC values. There was no significant effect of fluconazole alone on the reduction of biomass on fluconazoleresistant $C$. albicans biofilm. Furthermore, no significant effect was observed of amphotericin B alone on the reduction of biomass in amphotericin Bresistant isolates. The effect of fluconazole combined with amphotericin B significantly decreased the biomass on fluconazole-resistant $C$. albicans biofilm $(P<0.05)$.

The combination testing of fluconazole with amphotericin B on fluconazole-resistant C. albicans (ATCC 10231) biofilm formation was determined by the microscopic analysis of biofilm. Figure 1 shows the corresponding results for the reduction of biofilm, which resulted in the reduction of biofilm formation, hyphae and planktonic cells on fluconazole-resistant $C$. albicans treated with fluconazole combined with amphotericin B. As shown in the Figure 1, the fluconazole alone could not decrease the biofilm formation, hyphae and planktonic cells of fluconazoleresistant $C$. albicans compared to the untreated control $(P>0.05)$.

Our results indicated that the combination of fluconazole with amphotericin B on fluconazoleresistant $C$. albicans (ATCC 10231) biofilm formation exerted their antifungal effect through inhibition of the expression levels of $H W P 1 \quad(P \leq 0.05)$. No significant difference was observed in the mean of expression levels of $H W P 1$ on fluconazole-resistant $C$. albicans grown in the presence of fluconazole and amphotericin B alone $(P>0.05)$ (Figure 2 and Figure 3 ). 
Table 2. Relative MIC $(\mu \mathrm{g} / \mathrm{mL})$ and FIC values of fluconazole alone and in combination with amphotericin B against fluconazole-resistant $C$. albicans

\begin{tabular}{lccccccccc} 
& \multicolumn{2}{c}{ Flu } & \multicolumn{2}{c}{$\mathrm{AmB}$} & \multicolumn{2}{c}{ Flu/ AmB } \\
Isolates /Antifungals & $\mathrm{MIC}_{90}$ & $\mathrm{MIC}_{50}$ & $\mathrm{MIC}_{90}$ & $\mathrm{MIC}_{50}$ & $\mathrm{MIC}_{90}$ & $\mathrm{MIC}_{50}$ & FIC & Interpretive \\
C. albicans ATCC 10231 & 16 & 1 & 1 & 0.0156 & $4 / 0.5$ & $0.25 / 0.0313$ & 0.75 & PS \\
\hline C. albicans CBS 5982 & 0.125 & 0.0321 & 0.0313 & 0.0078 & $0.0625 / 0.0078$ & $0.0312 / 0.0039$ & 0.74 & PS \\
\hline CI-1 & 64 & 4 & 4 & 1 & $16 / 2$ & $2 / 0.5$ & 0.75 & PS \\
CI-2 & 16 & 8 & 4 & 0.5 & $16 / 2$ & $4 / 0.5$ & 1.5 & I \\
CI-3 & 32 & 16 & 4 & 2 & $8 / 1$ & $4 / 0.5$ & 0.5 & S \\
\hline CI-4 & 32 & 8 & 2 & 0.5 & $8 / 1$ & $2 / 0.25$ & 0.75 & PS \\
CI-5 & 32 & 8 & 4 & 0.5 & $16 / 2$ & $0.25 / 0.0625$ & 1 & A \\
\hline CI-6 & 64 & 4 & 1 & 0.5 & $16 / 2$ & $0.5 / 0.25$ & 2.25 & I \\
\hline CI-7 & 16 & 16 & 2 & 1 & $8 / 1$ & $4 / 0.5$ & 1 & A \\
\hline CI-8 & 32 & 8 & 4 & 2 & $8 / 1$ & $4 / 0.5$ & 0.5 & S \\
\hline CI-9 & 16 & 8 & 4 & 1 & $16 / 2$ & $0.25 / 0.0313$ & 1.5 & I \\
\hline CI-10 & 16 & 8 & 2 & 0.5 & $8 / 1$ & $2 / 0.25$ & 1 & A \\
\hline
\end{tabular}

CI: Clinical isolates of C. albicans, Flu: fluconazole, AmB: amphotericin B PS: Partial synergy; S: Synergy; A: Additive; I: Indifference Data are means of three independent experiments

Table 3. Biofilm formation assay using CV staining $(\mu \mathrm{g} / \mathrm{mL})$ on fluconazole-resistant $C$. albicans

\begin{tabular}{|c|c|c|c|c|c|c|c|c|c|c|c|c|c|}
\hline \multicolumn{2}{|c|}{$\begin{array}{c}\text { Concentration of } \\
\text { antifungal agents/ Isolates }\end{array}$} & \multirow{2}{*}{$\begin{array}{l}\text { C. albicans } \\
\text { ATCC } 10231 \\
0.32 \pm 0.15^{\mathrm{a}}\end{array}$} & \multirow{2}{*}{$\begin{array}{l}\text { C. albicans } \\
\text { CBS } 5982 \\
0.08 \pm 0.15^{\mathrm{a}}\end{array}$} & \multirow{2}{*}{$\begin{array}{l}\text { CI- } 1 \\
0.37 \pm 0.16^{\mathrm{a}}\end{array}$} & \multirow{2}{*}{$\begin{array}{c}\mathrm{CI}-2 \\
0.30 \pm 0.15^{\mathrm{a}}\end{array}$} & \multirow{2}{*}{$\begin{array}{c}\text { CI }-3 \\
0.35 \pm 0.15^{\mathrm{a}}\end{array}$} & \multirow{2}{*}{$\begin{array}{c}\text { CI-4 } \\
0.36 \pm 0.18^{\mathrm{a}}\end{array}$} & \multirow{2}{*}{$\begin{array}{c}\text { CI- } 5 \\
0.33 \pm 0.17^{\mathrm{a}}\end{array}$} & \multirow{2}{*}{$\begin{array}{c}\text { CI-6 } \\
0.35 \pm 0.15^{\mathrm{a}}\end{array}$} & \multirow{2}{*}{$\begin{array}{c}\text { CI-7 } \\
0.38 \pm 0.19^{a}\end{array}$} & \multirow{2}{*}{$\begin{array}{c}\text { CI- } 8 \\
0.38 \pm 0.18^{\mathrm{a}}\end{array}$} & \multirow{2}{*}{$\begin{array}{c}\text { CI-9 } \\
0.34 \pm 0.16^{a}\end{array}$} & \multirow{2}{*}{$\begin{array}{c}\text { CI- } 10 \\
0.37 \pm 0.19^{a}\end{array}$} \\
\hline Flu & $2 \times$ MIC & & & & & & & & & & & & \\
\hline & $1 \times$ MIC & $0.33 \pm 0.17^{\mathrm{b}}$ & $0.14 \pm 0.17^{\mathrm{b}}$ & $0.38 \pm 0.17^{\mathrm{b}}$ & $0.32 \pm 0.17^{\mathrm{c}}$ & $0.35 \pm 0.15^{\mathrm{a}}$ & $0.34 \pm 0.15^{\mathrm{b}}$ & $0.34 \pm 0.17^{\mathrm{b}}$ & $0.36 \pm 0.17^{\mathrm{b}}$ & $0.36 \pm 0.17^{\mathrm{b}}$ & $0.33 \pm 0.15^{b}$ & $0.35 \pm 0.15^{\mathrm{b}}$ & $0.37 \pm 0.16^{b}$ \\
\hline & $1 / 2 \times$ MIC & $0.38 \pm 0.16^{c}$ & $0.19 \pm 0.16^{c}$ & $0.38 \pm 0.16^{b}$ & $0.31 \pm 0.17^{\mathrm{b}}$ & $0.36 \pm 0.16^{b}$ & $0.33 \pm 0.17^{\circ}$ & $0.34 \pm 0.15^{\mathrm{b}}$ & $0.36 \pm 0.19^{\mathrm{b}}$ & $0.35 \pm 0.16^{\mathrm{c}}$ & $0.40 \pm 0.18^{\mathrm{c}}$ & $0.35 \pm 0.16^{c}$ & $0.39 \pm 0.16^{c}$ \\
\hline & $1 / 4 \times$ MIC & $0.38 \pm 0.16^{\circ}$ & $0.20 \pm 0.16^{\mathrm{d}}$ & $0.39 \pm 0.16^{\circ}$ & $0.32 \pm 0.17^{\circ}$ & $0.39 \pm 0.16^{\mathrm{c}}$ & $0.37 \pm 0.18^{d}$ & $0.38 \pm 0.16^{\mathrm{c}}$ & $0.37 \pm 0.16^{c}$ & $0.38 \pm 0.17^{d}$ & $0.41 \pm 0.17^{d}$ & $0.35 \pm 0.16^{\mathrm{d}}$ & $0.41 \pm 0.16^{d}$ \\
\hline & $\begin{array}{l}\text { Untreated } \\
\text { control }\end{array}$ & $0.49 \pm 0.16^{\mathrm{d}}$ & $0.49 \pm 0.16^{\circ}$ & $0.52 \pm 0.19^{\mathrm{d}}$ & $0.48 \pm 0.17^{\mathrm{d}}$ & $0.48 \pm 0.15^{\mathrm{d}}$ & $0.52 \pm 0.17^{\circ}$ & $0.47 \pm 0.19^{d}$ & $0.49 \pm 0.18^{\mathrm{d}}$ & $0.50 \pm 0.17^{\circ}$ & $0.52 \pm 0.18^{\mathrm{c}}$ & $0.48 \pm 0.15^{\mathrm{e}}$ & $0.51 \pm 0.15^{\circ}$ \\
\hline \multirow[t]{5}{*}{$\mathrm{AmB}$} & $2 \times$ MIC & $0.05 \pm 0.16^{\mathrm{a}}$ & $0.06 \pm 0.15^{\mathrm{a}}$ & $0.37 \pm 0.15^{\mathrm{a}}$ & $0.36 \pm 0.16^{\mathrm{a}}$ & $0.37 \pm 0.17^{\mathrm{a}}$ & $0.37 \pm 0.15^{\mathrm{a}}$ & $0.37 \pm 0.18^{\mathrm{a}}$ & $0.37 \pm 0.16^{\mathrm{a}}$ & $0.07 \pm 0.17^{\mathrm{a}}$ & $0.36 \pm 0.15^{\mathrm{a}}$ & $0.37 \pm 0.15^{\mathrm{a}}$ & $0.36 \pm 0.15^{\mathrm{a}}$ \\
\hline & $1 \times \mathrm{MIC}$ & $0.14 \pm 0.18^{\mathrm{b}}$ & $0.14 \pm 0.18^{b}$ & $0.35 \pm 0.17^{\mathrm{b}}$ & $0.42 \pm 0.17^{\mathrm{b}}$ & $0.38 \pm 0.17^{\mathrm{b}}$ & $0.36 \pm 0.17^{\mathrm{b}}$ & $0.35 \pm 0.17^{\mathrm{b}}$ & $0.37 \pm 0.16^{\mathrm{a}}$ & $0.12 \pm 0.19^{\mathrm{b}}$ & $0.32 \pm 0.15^{b}$ & $0.36 \pm 0.15^{b}$ & $0.37 \pm 0.15^{b}$ \\
\hline & $1 / 2 \times$ MIC & $0.18 \pm 0.16^{\circ}$ & $0.19 \pm 0.17^{\mathrm{c}}$ & $0.35 \pm 0.16^{b}$ & $0.42 \pm 0.16^{\mathrm{b}}$ & $0.38 \pm 0.17^{\mathrm{b}}$ & $0.36 \pm 0.19^{b}$ & $0.35 \pm 0.14^{\mathrm{b}}$ & $0.37 \pm 0.16^{\mathrm{a}}$ & $0.19 \pm 0.15^{\mathrm{c}}$ & $0.33 \pm 0.16^{\mathrm{c}}$ & $0.36 \pm 0.16^{b}$ & $0.37 \pm 0.16^{b}$ \\
\hline & $1 / 4 \times$ MIC & $0.20 \pm 0.17^{\mathrm{d}}$ & $0.20 \pm 0.18^{\mathrm{d}}$ & $0.41 \pm 0.16^{\circ}$ & $0.42 \pm 0.17^{\mathrm{b}}$ & $0.39 \pm 0.16^{\mathrm{c}}$ & $0.39 \pm 0.18^{\mathrm{c}}$ & $0.40 \pm 0.18^{c}$ & $0.39 \pm 0.16^{\mathrm{b}}$ & $0.20 \pm 0.15^{\mathrm{d}}$ & $0.33 \pm 0.17^{\mathrm{c}}$ & $0.36 \pm 0.19^{b}$ & $0.40 \pm 0.17^{\mathrm{c}}$ \\
\hline & $\begin{array}{l}\text { Untreated } \\
\text { control }\end{array}$ & $0.48 \pm 0.19^{\circ}$ & $0.49 \pm 0.18^{\mathrm{e}}$ & $0.48 \pm 0.19^{d}$ & $0.50 \pm 0.18^{c}$ & $0.49 \pm 0.19^{d}$ & $0.50 \pm 0.23^{d}$ & $0.50 \pm 0.15^{\mathrm{d}}$ & $0.49 \pm 0.16^{\mathrm{c}}$ & $0.49 \pm 0.21^{\circ}$ & $0.47 \pm 0.19^{d}$ & $0.49 \pm 0.19^{c}$ & $0.50 \pm 0.19^{d}$ \\
\hline \multirow[t]{5}{*}{$\begin{array}{l}\mathrm{Flu} / \\
\mathrm{AmB}\end{array}$} & $2 \times \mathrm{MIC}$ & $0.04 \pm 0.18^{\mathrm{a}}$ & $0.04 \pm 0.15^{\mathrm{a}}$ & $0.05 \pm 0.18^{\mathrm{a}}$ & $0.04 \pm 0.15^{\mathrm{a}}$ & $0.05 \pm 0.15^{\mathrm{a}}$ & $0.04 \pm 0.16^{\mathrm{a}}$ & $0.04 \pm 0.18^{\mathrm{a}}$ & $0.03 \pm 0.17^{\mathrm{a}}$ & $0.04 \pm 0.16^{\mathrm{a}}$ & $0.04 \pm 0.18^{\mathrm{a}}$ & $0.04 \pm 0.15^{\mathrm{a}}$ & $0.05 \pm 0.17^{\mathrm{a}}$ \\
\hline & $1 \times \mathrm{MIC}$ & $0.11 \pm 0.16^{b}$ & $0.10 \pm 0.16^{b}$ & $0.11 \pm 0.19^{b}$ & $0.11 \pm 0.15^{\mathrm{b}}$ & $0.10 \pm 0.15^{b}$ & $0.10 \pm 0.17^{b}$ & $0.10 \pm 0.17^{\mathrm{b}}$ & $0.11 \pm 0.17^{\mathrm{b}}$ & $0.11 \pm 0.17^{b}$ & $0.10 \pm 0.18^{b}$ & $0.12 \pm 0.15^{\mathrm{b}}$ & $0.10 \pm 0.17^{b}$ \\
\hline & $1 / 2 \times$ MIC & $0.15 \pm 0.16^{\mathrm{c}}$ & $0.13 \pm 0.16^{\mathrm{c}}$ & $0.16 \pm 0.16^{\mathrm{c}}$ & $0.18 \pm 0.16^{\mathrm{c}}$ & $0.17 \pm 0.15^{\mathrm{c}}$ & $0.17 \pm 0.17^{\mathrm{c}}$ & $0.16 \pm 0.15^{\mathrm{c}}$ & $0.18 \pm 0.17^{\circ}$ & $0.17 \pm 0.17^{\mathrm{c}}$ & $0.19 \pm 0.15^{\mathrm{c}}$ & $0.17 \pm 0.15^{\mathrm{c}}$ & $0.17 \pm 0.15^{c}$ \\
\hline & $1 / 4 \times$ MIC & $0.16 \pm 0.15^{\mathrm{d}}$ & $0.17 \pm 0.17^{\mathrm{d}}$ & $0.18 \pm 0.19^{d}$ & $0.19 \pm 0.15^{\mathrm{d}}$ & $0.19 \pm 0.15^{\mathrm{d}}$ & $0.18 \pm 0.15^{\mathrm{d}}$ & $0.18 \pm 0.15^{\mathrm{d}}$ & $0.19 \pm 0.16^{\mathrm{d}}$ & $0.18 \pm 0.17^{\mathrm{d}}$ & $0.21 \pm 0.19^{d}$ & $0.20 \pm 0.15^{\mathrm{d}}$ & $0.19 \pm 0.15^{\mathrm{d}}$ \\
\hline & $\begin{array}{l}\text { Untreated } \\
\text { control }\end{array}$ & $0.48 \pm 0.19^{c}$ & $0.47 \pm 0.15^{\circ}$ & $0.48 \pm 0.18^{\mathrm{e}}$ & $0.48 \pm 0.15^{\mathrm{e}}$ & $0.46 \pm 0.22^{\mathrm{e}}$ & $0.49 \pm 0.15^{\circ}$ & $0.49 \pm 0.15^{\circ}$ & $0.50 \pm 0.17^{\mathrm{e}}$ & $0.50 \pm 0.17^{\mathrm{e}}$ & $0.49 \pm 0.15^{\mathrm{c}}$ & $0.48 \pm 0.19^{e}$ & $0.48 \pm 0.15^{\circ}$ \\
\hline
\end{tabular}

CI: Clinical isolates of C. albicans, Flu: fluconazole, AmB: amphotericin B ${ }^{\text {a- }}$ e Means \pm SD in a column with different superscript differ significantly $(P<0.05)$ using Tukey's HSD test. The results were performed in three independent experiments 


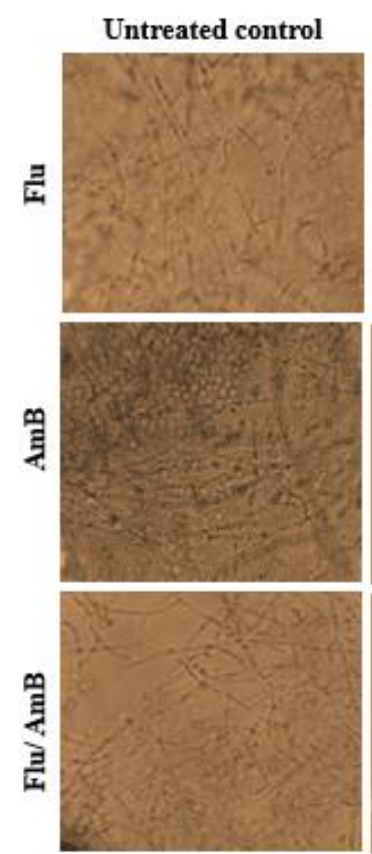

$50 \mu \mathrm{m}$
$2 \times$ MIC
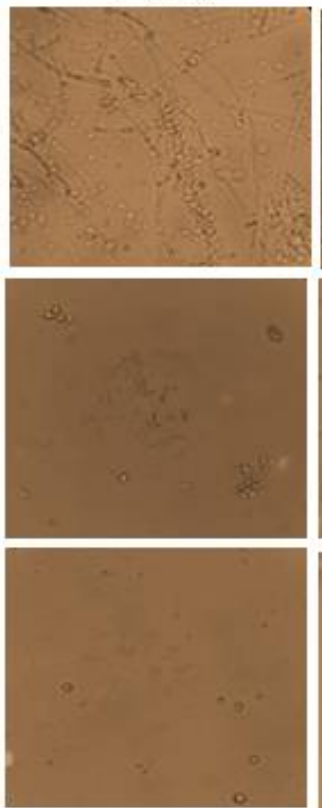

$50 \mu \mathrm{m}$
$1 \times$ MIC
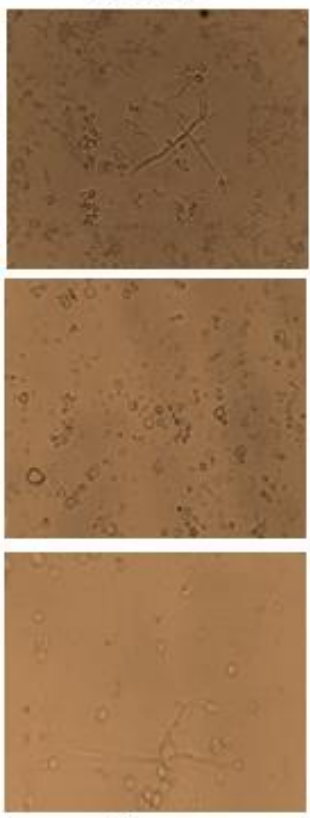

$50 \mu \mathrm{m}$
$1 / 2 \times$ MIC
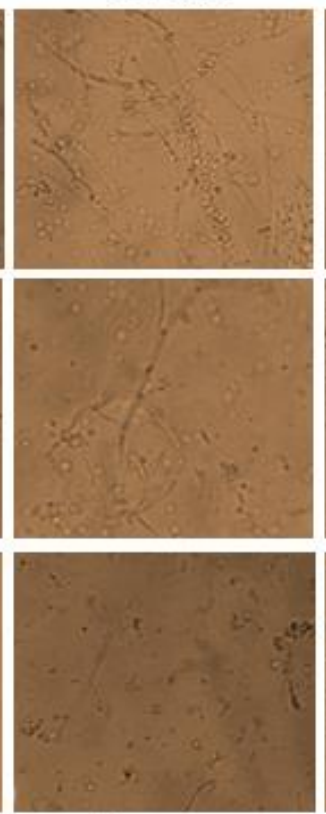

$50 \mu \mathrm{m}$
$1 / 4 \times$ MIC
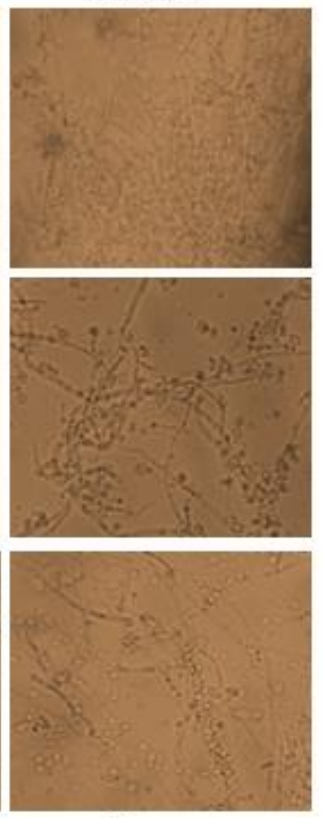

$50 \mu \mathrm{m}$

Figure 1. Light field microscopy of the inhibitory effect of fluconazole combined with amphotericin B on fluconazole-resistant $C$. albicans (ATCC 10231) biofilm formation at different concentrations. Magnification $\times 40$, Bar $=50 \mu \mathrm{m}$. Flu: fluconazole, AmB: amphotericin B.
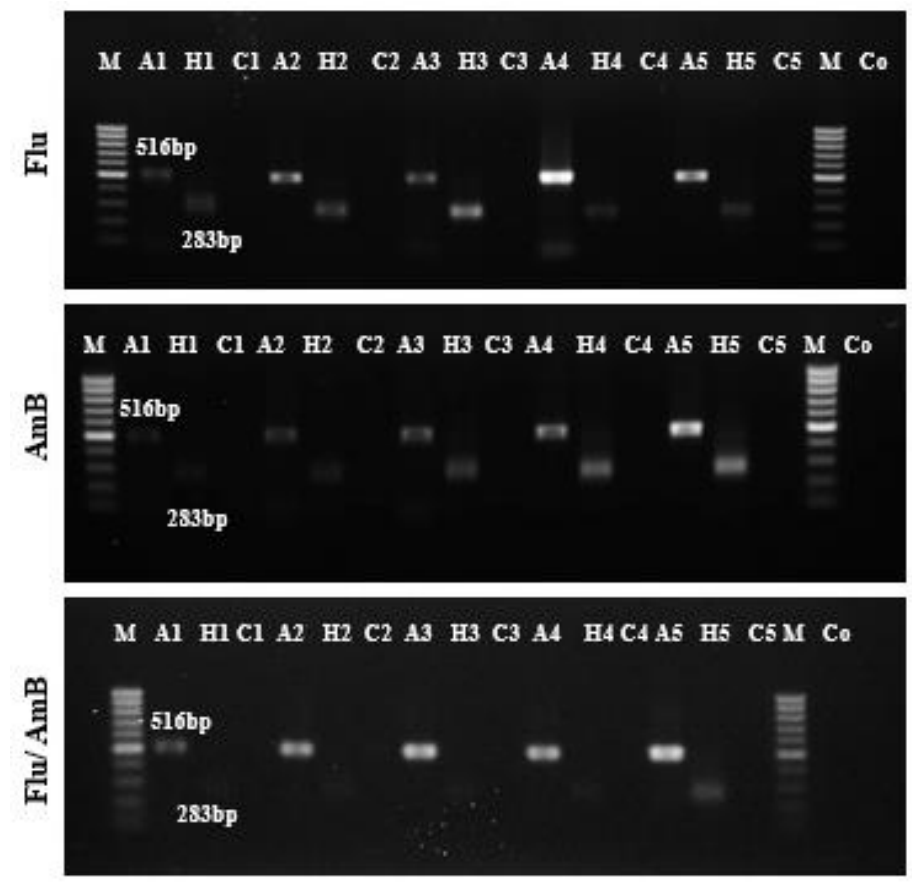

Figure 2. HWP1 expression in fluconazole-resistant $C$. albicans (ATCC 10231) biofilm treated with fluconazole combined with amphotericin B. M: 100 bp DNA Ladder, A1: Beta actin $(2 \times$ MIC), H1: HWP1 $(2 \times \mathrm{MIC}), \mathrm{C} 1$ : Internal control, A2: Beta actin $(1 \times \mathrm{MIC}), \mathrm{H} 2$ : HWP1 $(1 \times \mathrm{MIC}), \mathrm{C} 2$ : Internal control, A3: Beta actin $(1 / 2 \times \mathrm{MIC})$, H3: HWP1 ( $1 / 2 \times$ MIC), C3: Internal control, A4: Beta actin $(1 / 4 \times \mathrm{MIC}), \mathrm{H} 4$ : HWP1 $(1 / 4 \times \mathrm{MIC}), \mathrm{C} 4$ : Internal control, A5: Beta actin (untreated control), H5: HWP1 (untreated control). 


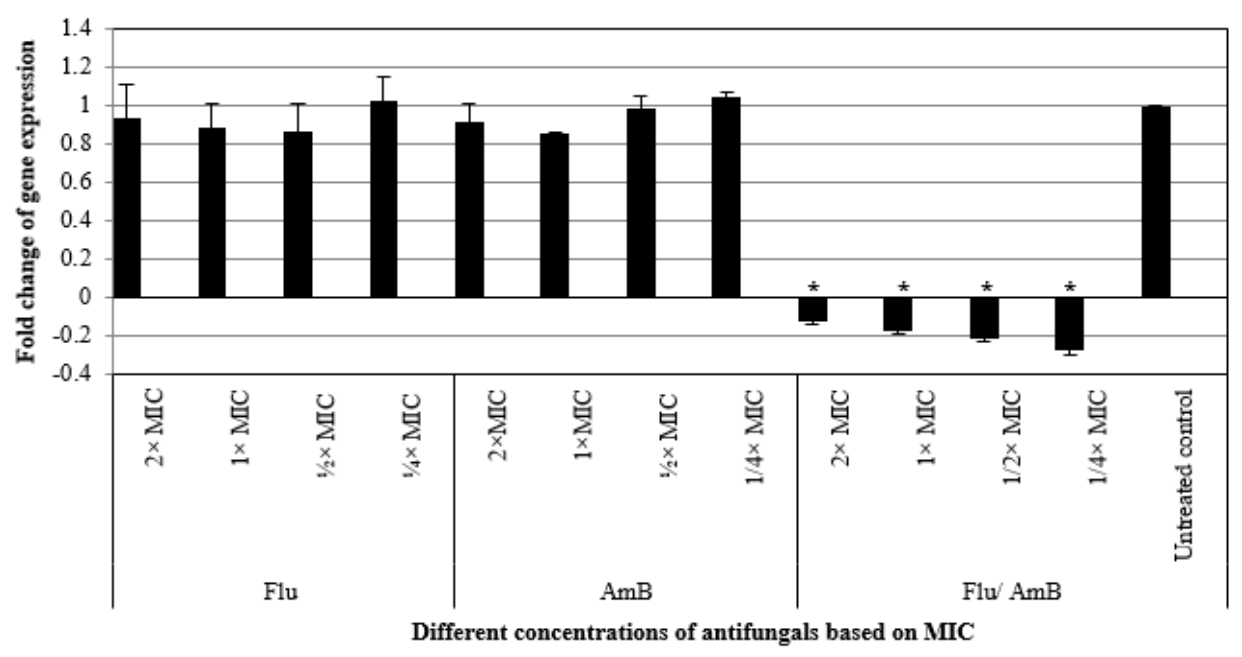

Figure 3. Relative gene expression levels of $H W P 1$ in combination of fluconazole with amphotericin $\mathrm{B}$ on fluconazole-resistant C. albicans (ATCC 10231) biofilm formation at different concentrations. Flu: fluconazole, AmB: amphotericin B.* Significant downregulation. Data are means of fold changes \pm SD from three independent experiments amplified in triplicates.

\section{Discussion}

In this study, we evaluated the inhibitory effect of fluconazole combined with amphotericin B against $C$. albicans. Our data supported the influences of fluconazole combined with amphotericin $\mathrm{B}$ against $C$. albicans. Although theoretically the use of fluconazole combined with amphotericin B may lead to the antagonism based on the specific modes of action of the azoles and polyenes, different reports have shown the inhibitory effect of fluconazole combined with amphotericin $\mathrm{B}$ against $C$. albicans $(13,15,22,23)$.

The frequency of biofilm-related infections caused by $C$. albicans has been increased disproportionately in the last few decades and become incurable because of the increasing number of immunocompromised hosts $(3,4)$. The current therapeutic options for the Candida infections are extremely limited as compared to those for the treatment of bacterial infections. The new formulations development for the antifungal drugs is not an easy task; only one new formulation of antifungal drugs has been created over the past 30 years. Several lines of evidence demonstrated that drug combinations are strategies to meet some of these challenges $(13,24)$.

In the present study we investigated the inhibitory effect of fluconazole combined with amphotericin B on fluconazoleresistant $C$. albicans biofilm formation. Our findings, based on the biomass inhibitory effects, consistently demonstrated that fluconazole combined with amphotericin B exerted a significant reduction on fluconazole-resistant $C$. albicans biofilm formation. Moreover, the morphological alterations on fluconazole-resistant $C$. albicans biofilms correlated well with the inhibitory effect of the fluconazole combined with amphotericin B treatments. In addition, fluconazole combined with amphotericin B indicated the inhibitory effect on HWPl gene that contributes to the biofilm formation. Since hyphal morphogenesis is a key virulence factor in $C$. albicans infection, the inhibition of $H W P 1$ could decrease the ability of $C$. albicans to cause the infection. $C$. albicans biofilms are intrinsically resistant to the various antifungal agents $(2,25)$. Combination therapy is an option for the eradication of Candida biofilm (26). Haque et al. (13) showed that combination of antifungal agents was the most effective against $C$. albicans biofilm.

However, the results of the present study demonstrated that fluconazole alone was not effective against fluconazoleresistant C. albicans biofilms in biomass reduction, morphological changes and the gene expression alterations. Although fluconazole has been proved as highly effective agent against Candida biofilms (27), there was no inhibitory effect observed on the fluconazole-resistant $C$. albicans biofilms. Several possible mechanisms of resistance to fluconazole have been identified in Candida species including genes involved in the ergosterol biosynthesis pathway, drug transporters, ploidy changes and loss of heterozygosity (28). In addition, the cells in a biofilm structure display a reduced susceptibility to azoles that target ergosterol biosynthesis pathway via possibly causing the ineffectiveness blockage of the enzyme lanosterol $14 \alpha$ demethylase (26).

Our results demonstrated that the amphotericin B alone exhibited inhibitory effects against fluconazole-resistant and amphotericin B susceptible C. albicans (ATCC 10231) biofilm. The amphotericin $\mathrm{B}$ application alone resulted in the reduction in biomass of the biofilm and morphological alterations at different concentrations against fluconazole- 
resistant C. albicans (ATCC 10231). Kuhn et al. (29) confirmed the resistance of mature $C$. albicans to the conventional antifungal agents. They demonstrated that lipid formulations of amphotericin B exhibited inhibitory effects against $C$. albicans biofilms. However, amphotericin B alone was not able to inhibit $H W P 1$ gene on fluconazole-resistant C. albicans biofilms. This result suggests that the amphotericin B alone may inhibit other genes involved in the biofilm development on fluconazole-resistant $C$. albicans.

\section{Conclusion}

In conclusion, these findings demonstrated that fluconazole combined with amphotericin B exhibits potent inhibitory effects against fluconazole-resistant $C$. albicans biofilm formation. Evaluating the treatment efficacy of fluconazole combined with amphotericin B against fluconazole-resistant $C$. albicans biofilm with other measures is important in determining the antifungal effectiveness.

\section{Acknowledgements}

The authors wish to thank the Islamic Azad University of Yasooj for financial support. Results of the current study are part of the MSc thesis (1280679).

\section{Conflict of Interest}

Authors declared no conflict of interests.

\section{References}

1. Desai JV, Mitchell AP, Andes DR. Fungal biofilms, drug resistance, and recurrent infection. Cold Spring Harb Perspect Med. 2014; 4(10): 1-18. [DOI:10.1101/cshperspect.a019729] [PMID] [PMCID]

2. Silva S, Rodrigues CF, Araújo D, Rodrigues ME, Henriques M. Candida species biofilms' antifungal resistance. J Fungi (Basel) 2017; 3(1): 2-17. [DOI:10.3390/jof3010008] [PMID] [PMCID]

3. Mitchell KF, Zarnowski R, Andes DR. Fungal super glue: the biofilm matrix and its composition, assembly, and functions. PLoS Pathog 2016; 12(9): 1-6. [DOI:10.1371/journal.ppat. 1005828] [PMID] [PMCID]

4. Pierce CG, Vila T, Romo JA, Montelongo-Jauregui D, Wall G, Ramasubramanian A, et al. The Candida albicans biofilm matrix: composition, structure and function. J Fungi (Basel). 2017; 3(1): 1-8. [DOI:10.3390/jof3010014] [PMID] [PMCID]

5. Bruzual I, Riggle P, Hadley S, Kumamoto CA. Biofilm formation by fluconazole-resistant Candida albicans strains is inhibited by fluconazole. J Antim Chem. 2007; 59(3): 441-50. [DOI:10.1093/jac/dkl521] [PMID]

6. Finkel JS, Mitchell AP. Genetic control of Candida albicans biofilm development. Nat Rev Microbiol. 2011; 9(2): 109-18. [DOI:10.1038/nrmicro2475] [PMID] [PMCID]
7. Desai JV, Mitchell AP. Candida albicans biofilm development and its genetic control. Microbiol Spectr. 2015; 3(3). [DOI:10.1128/microbiolspec.MB-0005-2014] [PMID] [PMCID]

8. Kean R, Delaney C, Rajendran R, Sherry L, Metcalfe R, Thomas R, et al. Gaining insights from Candida biofilm heterogeneity: one size does not fit all. J Fungi (Basel) 2018; 4(1): 1-20. [DOI:10.3390/jof4010012] [PMID] [PMCID]

9. Lohse MB, Gulati M, Johnson AD, Nobile CJ. Development and regulation of single- and multi-species Candida albicans biofilms. Nat Rev Microbiol. 2018; 16(1): 19-31. [DOI:10.1038/nrmicro.2017.107] [PMID] [PMCID]

10. Nobile CJ, Nett JE, Andes DR, Mitchell AP. Function of Candida albicans adhesin Hwp1 in biofilm formation. Eukaryot Cell. 2006; 5(10): 1604-10. [DOI:10.1128/EC. 00194-06] [PMID] [PMCID]

11. Staab JF, Datta K, Rhee P. Niche-specific requirement for hyphal wall protein 1 in virulence of Candida albicans. PLoS One 2013; 8(11): e80842. [DOI:10.1371/journal.pone .0080842] [PMID] [PMCID]

12. Li X, Hou Y, Yue L, Liu S, Duc J, Sun S. Potential targets for antifungal drug discovery based on growth and virulence in Candida albicans. Antim Agents Chem. 2015; 59(10): 588591. [DOI:10.1128/AAC.00726-15] [PMID] [PMCID]

13. Haque F, Ganesan AK, Shankar Bhattacharyya M. Inhibitory effect of sophorolipid on Candida albicans biofilm formation and hyphal growth. Sci Rep. 2016; 6: 23575. [DOI:10.1038/srep23575] [PMID] [PMCID]

14. Jia W, Zhang H, Li C, Li G, Liu X, Wei J. The calcineruin inhibitor cyclosporine a synergistically enhances the susceptibility of Candida albicans biofilms to fluconazole by multiple mechanisms. BMC Microbiol. 2016; 16(1): 113. [DOI:10.1186/s12866-016-0728-1] [PMID] [PMCID]

15. Sanati H, Ramos CF, Bayer AS, Ghannoum MA. Combination therapy with amphotericin B and fluconazole against invasive candidiasis in neutropenic-mouse and infective-endocarditis rabbit models. Antim Agents Chem. 1997; 41(6): 1345-8. [DOI:10.1128/AAC.41.6.1345]

16. CLSI (Clinical and Laboratory Standards Institute). Reference method for broth dilution antifungal susceptibility testing of yeasts; Approved standard M27-A3. 3rd ed. Wayne, PA: Clinical and Laboratory Standards Institute; 2008.

17. George M, Eliopoulos GM, Robert C, Moellering JR. Antimicrobial combinations. Antibiotics in laboratory medicine. Baltimore: The Williams and Wilkins; 1996.

18. Peeters E, Nelis HJ, Coenye T. Comparison of multiple methods for quantification of microbial biofilms grown in microtiter plates. J Microbiol Methods. 2008; 72(2): 157- 65. [DOI:10.1016/j.mimet.2007.11.010] [PMID]

19. Braga PC, Culici M, Alfieri M, Dal Sasso M. Thymol inhibits Candida albicans biofilm formation and mature biofilm. Int $\mathrm{J}$ Antimicrob Agents. 2008; 31(5): 472-7. [DOI:10.1016/j.ijan timicag.2007.12.013] [PMID]

20. Low CF, Chong PP, Yong PVC, Lim CSY, Ahmad Z, Othman F. Inhibition of hyphae formation and SIR2 expression in Candida albicans treated with fresh Allium sativum (garlic) extract. J Appl Microbiol. 2008; 105(6): 216977. [DOI:10.1111/j.1365-2672.2008.03912.x] [PMID] 
21. Khodavandi A, Harmal NH, Alizadeh F, Scully OJ, Sidik SHM, Othman F, et al. Comparison between allicin and fluconazole in Candida albicans biofilm inhibition and in suppression of $H W P 1$ gene expression. Phytomedicine. 2011; 19(1): 56-63. [DOI:10.1016/j.phymed.2011.08.060] [PMID]

22. Shojaei E, Falahati M, Zaini F, Kord bache P, Rahimi moghadam P, Aghamirian M, et al. Effects of several common antifungal drugs (clotrimazole, miconazole, fluconazole) alone and in combination with amphotericin B on Candida species isolated from chronic Candidal vulvovaginitis. J Fasa Univ Med Sci. 2014; 4(3): 327-34.

23. Johnson MD, MacDougall C, Ostrosky-Zeichner L, Perfect JR, Rex JH. Combination antifungal therapy. Antim Agents Chem 2004; 48: 693-715. [DOI:10.1128/AAC.48.3.693715.2004] [PMID] [PMCID]

24. Roemer T, Krysan DJ. Antifungal drug development: challenges, unmet clinical needs, and new approaches. Cold Spring Harb Perspect Med. 2014; 4(5). pii: a019703. [DOI:10.1101/cshperspect.a019703] [PMID] [PMCID]
25. Nobile CJ, Johnson AD. Candida albicans biofilms and human disease. Annu Rev Microbiol. 2015; 69: 71-92. [DOI:10.1146/ annurev-micro-091014-104330] [PMID] [PMCID]

26. Mathé L, Van Dijck P. Recent insights into Candida albicans biofilm resistance mechanisms. Curr Genet. 2013; 59(4): 25164. [DOI:10.1007/s00294-013-0400-3] [PMID] [PMCID]

27. Bink A, Pellens K, Cammue BPA, Thevissen K. Anti-biofilm strategies: how to eradicate Candida biofilms? Open Mycol J. 2011; 5: 29-38. [DOI:10.2174/1874437 001105010029]

28. Berkow EL, Lockhart SR. Fluconazole resistance in Candida species: a current perspective. Infect Drug Resist 2017; 10: 237-45. [DOI:10.2147/IDR.S118892] [PMID] [PMCID]

29. Kuhn DM, George T, Chandra J, Mukherjee PK, Ghannoum MA. Antifungal susceptibility of Candida biofilms: unique efficacy of amphotericin B lipid formulations and echinocandins. J Antimicrob Chemother. 2002; 46(6): 17731780. [DOI:10.1128/AAC.46.6.1773-1780.2002] [PMID] [PMCID]

\section{How to Cite This Article:}

Neamati S, Khodavandi A, Alizadeh F Inhibitory Effect of Fluconazole Combined with Amphotericin B on Fluconazole-Resistant Candida albicans Biofilm Formation. J Adv Med Biomed Res. 2019; 27 (122):1-8

\section{Download citation:}

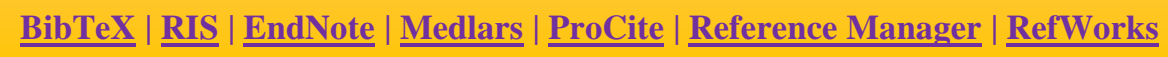

\section{Send citation to:}

(6) Mendeley $2 \underline{\text { Zotero }}$ (i) RefWorks $\underline{\text { RefWorks }}$ 